\title{
BAKing up to Survive a Battle: Functional Dynamics of BAK1 in Plant Programmed Cell Death
}

\author{
Xiquan Gao ${ }^{1,2 *}$, Xinsen Ruan ${ }^{1,2}$, Yali Sun ${ }^{1,2}$, Xiue Wang ${ }^{1,2}$ and Baomin Feng ${ }^{3 *}$ \\ ${ }^{1}$ State Key Laboratory of Crop Genetics and Germplasm Enhancement, Nanjing Agricultural University, Nanjing, China, \\ 2 Jiangsu Collaborative Innovation Center for Modern Crop Production, Nanjing Agricultural University, Nanjing, China, \\ ${ }^{3}$ Haixia Institute of Science and Technology, Fujian Agricultural and Forestry University, Fuzhou, China
}

OPEN ACCESS

Edited by:

Yi Li,

Peking University, China

Reviewed by:

Irene Serrano,

Georg-August-Universität Göttingen,

Germany

Yusuke Saijo,

Nara Institute of Science and Technology (NAIST), Japan

*Correspondence:

Xiquan Gao

xgao@njau.edu.cn

Baomin Feng

baomin2006@126.com

Specialty section:

This article was submitted to

Plant Microbe Interactions,

a section of the journal

Frontiers in Plant Science

Received: 04 May 2018

Accepted: 10 December 2018

Published: 08 January 2019

Citation:

Gao X, Ruan X, Sun Y, Wang X and Feng $B$ (2019) BAKing up

to Survive a Battle: Functional

Dynamics of BAK1 in Plant

Programmed Cell Death.

Front. Plant Sci. 9:1913.

doi: 10.3389/fp/s.2018.01913
In plants, programmed cell death (PCD) has diverse, essential roles in vegetative and reproductive development, and in the responses to abiotic and biotic stresses. Despite the rapid progress in understanding the occurrence and functions of the diverse forms of PCD in plants, the signaling components and molecular mechanisms underlying the core PCD machinery remain a mystery. The roles of BAK1 (BRASSINOSTEROID INSENSITIVE 1-associated receptor kinase 1), an essential co-receptor of multiple receptor complexes, in the regulation of immunity and development- and defenserelated PCD have been well characterized. However, the ways in which BAK1 functions in mediating PCD need to be further explored. In this review, different forms of PCD in both plants and mammals are discussed. Moreover, we mainly summarize recent advances in elucidating the functions and possible mechanisms of BAK1 in controlling diverse forms of PCD. We also highlight the involvement of post-translational modifications (PTMs) of multiple signaling component proteins in BAK1-mediated PCD.

Keywords: BAK1, development, co-receptor, programmed cell death, immunity

\section{INTRODUCTION}

Plants have evolved surveillance systems and cellular responses to sustain their growth while protecting themselves against various environmental stresses, often through deploying programmed cell death (PCD) to balance the survival signaling with proper development patterns and abiotic stresses or microbial infections (Van Hautegem et al., 2015; Kabbage et al., 2017). In response to microbial invasions, plants reply on cell surface receptor proteins to detect extracellular molecules produced by pathogens, collectively called pathogen-associated molecular patterns (PAMPs) and activate the PAMP-triggered immunity (PTI) pathway (Zipfel, 2014; Bigeard et al., 2015). Typical PTI responses include callose deposition, ROS production, and the expression of specific marker genes (Jones and Dangl, 2006). The receptor proteins located on plant cell surface that perceive PAMPs are known as pattern-recognition receptors (PRRs), which include receptor kinases (RKs) and receptor-like proteins (RLPs; Song et al., 1995; Gomez-Gomez and Boller, 2000; Chinchilla et al., 2006; Zipfel et al., 2006; Dardick et al., 2012).

In addition to PTI, a second layer of plant defense detects the presence of effector proteins from pathogens by intracellular immune receptor proteins, most of which are nucleotide-binding site leucine-rich repeat (NB-LRR or NLR) proteins and trigger robust immune responses, including ROS production, activation of specific effector-triggered immunity (ETI) marker genes, and rapid 
collapse of living tissues named as hypersensitive response (HR), a type of plant-specific PCD. PCD may limit the spread of pathogens; under other stresses, PCD may allow the recycling of nutrients to sustain growth (Jones and Dangl, 2006; Caplan et al., 2008; Eitas and Dangl, 2010; Feng and Zhou, 2012). In plant-microbe interactions, PCD has been recognized as a hallmark of ETI, and also important responses in certain PTI processes (Jones and Dangl, 2006; Caplan et al., 2008; Eitas and Dangl, 2010; Coll et al., 2011; Feng and Zhou, 2012). Other works revealed that PCD is a common and fundamental process that occurs in most eukaryotic organisms (Danon et al., 2000; Ameisen, 2002). PCD is also an intrinsic and indispensable process for plant vegetative and reproductive development. For example, differentiation and maturation of tracheary elements, and abscission of floral organs and tapetum degeneration all involve PCD. PCD was first reported in animals, where it serves as a mechanism to remove unwanted or damaged cells through development-related cell suicide and disease-related cell death (Zakeri et al., 1995; Raff, 1998).

Interestingly, plant PCD associated with development and immunity seems to be often connected to a cell-surface localized receptor kinase named BRI1-associated receptor kinase 1 (BAK1) (Chinchilla et al., 2007; Heese et al., 2007; Chinchilla et al., 2009; Ma et al., 2016). BAK1 was originally discovered as a key component of brassinosteroid (BR) signaling. Research in past decades demonstrated that BAK1 functions as a coreceptor in multifaceted receptor complexes to regulate a variety of processes, including BR-dependent development involving the receptor BRASSINOSTEROID INSENSITIVE 1-(BRI1), and Flagellin-Sensitive 2 (FLS2)-dependent PTI responses (Chinchilla et al., 2009; Ma et al., 2016). Readers who are interested in the topics about the role of BAK1 in innate immunity are strongly suggested to refer to several recent excellent reviews and herein (Ma et al., 2016; Yamada et al., 2016; Yasuda et al., 2017).

There is growing evidence to suggest that BAK1 plays an essential role in regulating various types of PCD ( $\mathrm{He}$ et al., 2007; Kemmerling et al., 2007; Gao et al., 2009; Schwessinger et al., 2011; Gao et al., 2013b; de Oliveira et al., 2016; Du et al., 2016). The current review will focus primarily on the recent progress made in elucidating the functions of BAK1 in both development- and immunity-associated cell death. The possible mechanisms underlying BAK1-mediated cell death via its cooperation with multiple signaling components and its diverse regulatory mechanisms, including post-translational modification (PTM), will also be discussed.

\section{PCD IN PLANTS}

\section{Unique Features of Plant Cell Death}

Based on the cell morphology, cell death in mammalian cells was classified into three types: apoptosis, autophagy, and necrosis (Zakeri et al., 1995; Kroemer et al., 2009; van Doorn, 2011). These three different types of cell death have different causes and different regulatory mechanisms. Apoptosis is characterized by early collapse and condensation of the nucleus, fragmentation of chromatin, generation of nucleosomal ladders, nuclear blebbing, and cytoplasmic condensation (Zakeri et al., 1995; Yu et al., 2002). The typical biochemical features of apoptosis include DNA cleavage, degradation of the DNA repair enzyme poly (ADP ribose) polymerase, and activation of caspases, a group of cysteine protease (Yu et al., 2002). Autophagy is normally characterized by an increase in the abundance of lytic vesicles termed autophagosomes (Berry and Baehrecke, 2008; Xu et al., 2015), and is regulated by a number of autophagy-related genes (ATGs) (Zhang and Tang, 2005; Patel et al., 2006; Berry and Baehrecke, 2008; Xu et al., 2015). Necrosis is typically accompanied by cell and organelle swelling, rupture of organelles and the plasma membrane, increases in ROS and calcium in cytoplasm, and decreases in cellular ATP (Farber, 1994; Postel et al., 2010; Heller et al., 2018). PCD is also involved in numerous biological processes in plants (Greenberg, 1996; Beers, 1997; Pennell and Lamb, 1997; Lam et al., 1999; Van Hautegem et al., 2015), such as cell differentiation and regulation of cell number, embryogenesis (Bozhkov et al., 2005), abiotic stress responses (Gepstein and Glick, 2013), and plant-pathogen interactions (Beers, 1997; Greenberg, 1997; Coll et al., 2011). Compared to animals, plants are sessile and plant cell surface is coated with much larger number of receptor proteins ( 600 RLK RLPs in Arabidopsis genome) (Tang et al., 2017), therefore, plant is thought to deploy differential, yet complexity strategies of PCD to adapt to diverse and harsh environmental stresses. To better understand the similarities and differences of PCD between plant and animal kingdoms, readers are suggested to refer to several excellent reviews (Kroemer et al., 2009; van Doorn, 2011; Rantong and Gunawardena, 2015; Dickman et al., 2017; Kabbage et al., 2017).

There are several commonalities of PCD features between plants and animals, including the existence of apoptosis-like morphological features and caspase-like proteases, as well as ATG genes in plants (Dickman et al., 2017; Kabbage et al., 2017). The hallmarks of PCD in mammalian systems, including the formation of apoptotic bodies and DNA cleavage (Mittler et al., 1995; Levine et al., 1996; Wang et al., 1996), also exist in plants (Greenberg, 1996). For example, in Nicotiana benthamiana, BECLIN 1, an ortholog of yeast ATG6/VPS30 and mammalian beclin 1 has been identified and characterized as a key regulator in both developmental and HR-type PCD. BECLIN 1 deficient $N$. benthamiana plants showed accelerated leaf senescence, while the HR-type cell death was suppressed in BECLIN1-silenced plants (Liu et al., 2005). However, many of the features and precise mechanisms of plant PCD are not fully understood.

Several features of PCD are distinct in plant cells, involving different types of caspases and phagocytosis systems compared with those in mammalian cells; the mechanisms involved in plant PCD differ from those in animal PCD, probably due to the genetic and functional redundancy of PCD components as well as plantspecific cellular features such as rigid cell walls, totipotency, and the presence of chloroplasts (Williams and Dickman, 2008).

The nature of apoptosis in plants is controversial. For instance, the viable aleurone cells of mature barley seeds undergo PCD when the seed starts to germinate, and the cells become highly vacuolated; however, aleurone cell death at this stage does 
not display the hallmarks of mammalian apoptosis-like PCD, probably due to the absence of major animal apoptosis regulators in plants (Fath et al., 2000; Dickman et al., 2017; Kabbage et al., 2017). Intriguingly, treatments with the Fumonisin B1 mycotoxin or abiotic stresses can trigger the formation of apoptosis-like bodies in plants (Li and Dickman, 2004; Li W. et al., 2010); therefore, caution should be paid when the presence of apoptosis-like cell death in plants is proposed (Dickman et al., 2017). Moreover, during senescence and the differentiation of the tracheary elements, cell death-associated physiological changes often involve vacuole collapse, providing evidence for the essential role of the vacuole in plant PCD (Jones, 2001). Besides vacuole, other organelles, including mitochondria and chloroplasts, have also been suggested to function in plant PCD (Lam et al., 2001).

Numerous environmental factors can trigger PCD, including salt (Li et al., 2007), drought (Duan et al., 2010; Hameed et al., 2013), ozone (Overmyer et al., 2005), and heat (Zuppini et al., 2007; Li Z. et al., 2012). When Arabidopsis roots were subjected to water deficit stress, for example, the typical features of PCD, including increased vacuole size, organelle degradation, and the collapse of tonoplast and plasma membrane, were observed in the apical meristem of the Arabidopsis primary root (Duan et al., 2010). Prolonged salt stress for $24 \mathrm{~h}$ caused by treatment with either $\mathrm{NaCl}$ or $\mathrm{KCl}$ resulted in the significant degradation of organelles in the green algae Micrasterias denticulate (Affenzeller et al., 2009). All together, these studies point to the existence and complexity of different forms of PCD in plants, in response to differential types of stresses. It has to be noted that, however, it remains enigmatic whether a common core machinery is shared for different types of PCD upon perception of either developmental or various abiotic or biotic stress cues (Huysmans et al., 2017).

\section{Classification of PCD in Plants}

The classification of PCD in plants is contradictory, depending on the criteria. It was divided previously into two classes based on morphological features: vacuolar cell death and necrosis (van Doorn et al., 2011) but later updated to autolytic and non-autolytic cell death (van Doorn, 2011). Based on the triggers of PCD in plants, however, several previous studies have suggested that PCD could be classified into development-related PCD (dPCD), environment-related PCD (ePCD), and pathogentriggered PCD (pPCD) (Daneva et al., 2016; Huysmans et al., 2017). dPCD is morphologically characterized by senescence, vacuolar collapse, nuclear degeneration or fragmentation, and cell elimination, which facilitates the successful establishment of reproductive organ identity and structural determination (Daneva et al., 2016). dPCD also occurs during vegetative development in plants, such as xylogenesis, as well as in organ abscission and dehiscence, where it is characterized by tonoplast rupture, vacuolar content release, mitochondrial degradation, and cytoplasmic clearance (Kuriyama, 1999; Yu et al., 2002). ePCD is thought to arise as a response to stress caused by diverse environmental conditions, including abiotic and biotic factors (Wu et al., 2014; Petrov et al., 2015). To better conceptually delineate the mechanisms involved in PCD, we propose that PCD is classified into $\mathrm{APCD}$, aPCD (abiotic stress-related PCD), and bPCD (biotic stress-related PCD). Currently, there is very limited information for the direct function of BAK1 in controlling aPCD; therefore, we will only focus on the involvement of BAK1 in the regulation of $\mathrm{APCD}$ and $\mathrm{BPCD}$ in the following sections.

\section{BAK1 IS INVOLVED IN THE REGULATION OF DIVERSE FORMS OF PCD}

BAK1 belongs to the SERK (somatic embryogenesis-related kinase) family, which are a small group of membrane-localized RLKs that can perceive diverse extracellular ligand stimuli and relay these signals, normally via a phosphorylation cascade (Li, 2010). The first plant SERK identified, DcSERK, was detected in carrot (Daucus carota) hypocotyl cell suspension cultures (Schmidt et al., 1997) during a search for marker genes to enable the monitoring of the transition from somatic cells into embryogenic cells. Most SERKs contain a small extracellular LRR-domain with five repeats, a single transmembrane domain, and a cytoplasmic kinase domain (Li, 2010). The Arabidopsis thaliana genome encodes five SERKs, AtSERK1, AtSERK2, AtSERK3, AtSERK4, and AtSERK5, which arose through gene duplication (Aan den Toorn et al., 2015). Baudino et al. (2001) isolated and identified maize (Zea mays) ZmSERK1 and ZmSERK2 using degenerate primers based on DcSERK and AtSERK1, and ZmSERK3/BAK1 was later characterized for its function in embryogenesis (Zhang et al., 2011). Identification of SERK homologs in sequenced genomes of both higher plants and lower plants, such as moss (Physcomitrella patens), suggests an evolutionarily conserved significance of SERKs (Aan den Toorn et al., 2015).

To date, numerous genetic and biochemical studies have demonstrated that BAK1 functions as a master player at the convergence of multiple physiological processes, including the regulation of development, and responses to biotic stresses (Heese et al., 2007; Chinchilla et al., 2009; Schwessinger et al., 2011; Shen et al., 2011; Meng et al., 2015). For instance, BAK1 participates in BR signaling, vascular differentiation, stem elongation, flowering, floral abscission, fertility, and senescence (Li et al., 2002; Nam and Li, 2002; Postel et al., 2010; Meng et al., 2016). It was also reported to function in PHYTOSULFOKINE alpha (PSK)-regulated root growth (Ladwig et al., 2015), ERECTA (ER) and EPIDERMAL PATTERNING FACTORS (EPFs)dependent cell fate specification in stomatal patterning (Meng et al., 2015).

How can BAK1 as a single RLK participate in so many different signaling pathways? One important reason is that BAK1 could function as a co-receptor or signaling regulator of multiple receptor kinases and RLPs; for example, BAK1 forms complexes with BRI1 to activate BR signaling, and with FLS2 to regulate a PTI pathway (Nam and Li, 2002; Chinchilla et al., 2007; Kemmerling et al., 2007; Ma et al., 2016). Additionally, BAK1 cooperates with multiple immune-related RLKs or RLPs at either the plasma membrane 
TABLE 1 | Different forms of BAK1-mediated PCD in plants.

\begin{tabular}{|c|c|c|c|c|c|c|}
\hline PCD type & Trigger of PCD & Receptor & $\begin{array}{l}\text { Perturbation of } \\
\text { BAK1 function }\end{array}$ & PCD phenotype & $\begin{array}{l}\text { Possible } \\
\text { Regulation }\end{array}$ & Reference \\
\hline \multirow[t]{7}{*}{$\begin{array}{l}\text { PCD by disruption } \\
\text { of BAK1 and } \\
\text { related proteins }\end{array}$} & bkk1/serk4 & & bak1 & $\begin{array}{l}\text { Spontaneous cell } \\
\text { death }\end{array}$ & $\begin{array}{l}\text { Phosphorylation; } \\
\text { Glycosylation }\end{array}$ & $\begin{array}{l}\text { He et al., 2007; } \\
\text { Kemmerling et al., } \\
\text { 2007; Jeong et al., } \\
\text { 2010; de Oliveira } \\
\text { et al., } 2016\end{array}$ \\
\hline & SOBIR1 OE & & NA & $\begin{array}{l}\text { Spontaneous cell } \\
\text { death }\end{array}$ & Phosphorylation & $\begin{array}{l}\text { Gao et al., 2009; } \\
\text { Liebrand et al., } \\
2014\end{array}$ \\
\hline & bir1 & & bak1 & $\begin{array}{l}\text { Spontaneous cell } \\
\text { death dependent } \\
\text { on SOBIR1 }\end{array}$ & Phosphorylation & Gao et al., 2009 \\
\hline & bir3 & & bak1 & Enhanced HR & Phosphorylation & $\begin{array}{l}\text { Halter et al., 2014; } \\
\text { Imkampe et al., } \\
2017\end{array}$ \\
\hline & bon1 & & NA & $\begin{array}{l}\text { Spontaneous cell } \\
\text { death }\end{array}$ & Phosphorylation & $\begin{array}{l}\text { Wang et al., 2011; } \\
\text { Kim et al., 2017; }\end{array}$ \\
\hline & CRK28 OE & & NbSerk3 silencing & Suppressed HR & Glycosylation & $\begin{array}{l}\text { Yadeta et al., 2016, } \\
2017\end{array}$ \\
\hline & bir1pad4-1 & & sobir7-1/bak1 & Suppressed HR & & $\begin{array}{l}\text { Liu et al., 2016; Wu } \\
\text { et al., } 2018\end{array}$ \\
\hline \multirow[t]{5}{*}{ bPCD by PAMPs } & SCFE1 (Sclerotnia) & RLP30-SOBIR1 & bak1 & suppressed HR & & Zhang et al., 2013 \\
\hline & BcScp1 (Botrytis) & & bak1 & Suppressed HR & & $\begin{array}{l}\text { Dagvadorj et al., } \\
2017\end{array}$ \\
\hline & Eix (fungal) & $\begin{array}{l}\text { LeEix } 1 / 2 \\
\text { (LRR-RLP) }\end{array}$ & BAK1 silencing & Suppressed HR & & Bar et al., 2010 \\
\hline & $\begin{array}{l}\text { Pst SCR1 (Puccinia } \\
\text { stratiform) }\end{array}$ & & bak1 & Suppressed HR & & $\begin{array}{l}\text { Dagvadorj et al., } \\
2017\end{array}$ \\
\hline & pep2 & PEPR & bak1 & Enhanced HR & & $\begin{array}{l}\text { Yamada et al., } \\
2016\end{array}$ \\
\hline \multirow{2}{*}{$\begin{array}{l}\text { bPCD upon } \\
\text { pathogen }\end{array}$} & $\mathrm{Hpa}$ & & bak1 & Enhanced HR & & Heese et al., 2007 \\
\hline & Alternaria & & bir2 & Enhanced HR & & Halter et al., 2014 \\
\hline \multirow[t]{3}{*}{ bPCD by effector } & Aphid & $\mathrm{Mi}-1$ (NLR) & bak1 & Suppressed HR & & Peng et al., 2016 \\
\hline & FolAvr1 (Fusarium) & I (LRR LRP) & bak1 & Suppressed HR & & $\begin{array}{l}\text { Catanzariti et al., } \\
2017\end{array}$ \\
\hline & $\begin{array}{l}\text { Avr } 4 / 9 \\
\text { (Cladosporium) }\end{array}$ & Cf-4, Cf-9 & bak1 & Suppressed HR & Endocytosis & Postma et al., 2016 \\
\hline \multirow[t]{3}{*}{ dPCD } & TDIF & PXY & bak1 & $\begin{array}{l}\text { Treachery element } \\
\text { PCD }\end{array}$ & & $\begin{array}{l}\text { Ma et al., 2016; } \\
\text { Zhang et al., } 2016\end{array}$ \\
\hline & TPD1 & EMS1 & serk1/2 & Tapetal PCD & & Li Z. et al., 2017 \\
\hline & IDA & HSA/HSL2 & serk1/2/3 & PCD in abscission & & Meng et al., 2016 \\
\hline
\end{tabular}


or in the cytoplasm, modulating distinct $\mathrm{PCD}$ processes (Table 1).

\section{BAK1 in Controlling dPCD}

Numerous studies have revealed that BAK1 plays crucial roles in regulating dPCD; for example, silencing GhBAK1 in cotton (Gossypium hirsutum) triggers high levels of cell death accompanied by increased ROS production, suggesting that the regulation of cell death by BAK1 is conserved in diverse plant species (Gao et al., 2013b). Interestingly, the BAK1 homolog, SERK5, does not regulate cell death in the Arabidopsis ecotype Col-0, whereas in the ecotype Landsberg erecta it has a regulatory role in cell death (Wu et al., 2015). The serine/threonine protein kinase BOTRYTIS-INDUCED KINASE 1 (BIK1) functions with BAK1; in the baklbik1 double mutant, a constitutive immune response and spontaneous cell death causes severe growth defects and a dwarf phenotype, accompanied with enhanced expression levels of immune genes, including PR1, PR5, PAD4, WRKY45, and ERF1 (Liu et al., 2017). Additionally, BAK1 interacts with BIR1 (BAK1-interacting receptor-like kinase 1), and the bir1 mutant displays a constitutive cell death phenotype (Gao et al., 2009). Both BAK1 and BIR1 interact in vitro and in vivo with BONZAI1 (BON1), a calcium-dependent phospholipid-binding protein; bon 1 mutants genetically interacted with birl to produce temperature-dependent growth defects and cell death in Arabidopsis (Wang et al., 2011).

It has been noted that BAK1, together with other SERK family members, could function as a co-receptor of PXY (phloem intercalated with xylem) (Zhang et al., 2016). PXY is a LRR-RLK receptor of tracheary element differentiation inhibitory factor (TDIF), also known as CLAVATA3/EMBRYO SURROUNDING REGION-RELATED (CLE), which regulates vascular development in Arabidopsis, revealing the involvement of these essential components in dPCD (Ma et al., 2016; Zhang et al., 2016). It has been demonstrated that tracheary elements (TEs) typically undergo an autophagic type of PCD during differentiation in Zinnia elegans and Arabidopsis (Fukuda, 1997; Fukuda, 2000; Turner et al., 2007; Williams and Dickman, 2008). This type of PCD is characterized by a clearing process for the removal of dead protoplasts, normally achieved by multiple proteases, including xylem cysteine proteases 1 and 2 (XCP1 and XCP2), bifunctional nuclease 1/endonuclease 1 (BFN1/ENDO1) and metacaspase 9 (MC9) (Avci et al., 2008; Bollhoner et al., 2013; Xu et al., 2018). Some transcriptional factors, such as VASCULAR-RELATED NAC-DOMAIN6/7 (VND6/7), appear to also be responsible for the PCD process activated by TDIF signaling (Ito and Fukuda, 2002; Pyo et al., 2007; Zhong et al., 2010; Heo et al., 2017). However, evidence supporting that BAK1 directly regulates $\mathrm{APCD}$ is still missing.

Intriguingly, BR signaling was also found to be involved in xylem differentiation, as evidenced by the findings that treatment using the BR signaling inhibitor brassinazole, and the BR biosynthesis inhibitor uniconazole, resulted in aberrant vascular patterning and PCD (Yamamoto et al., 1997; Asami et al., 2000), while the BR deficient mutant, $c p d$ (photomorphogenic dwarf) showed defective xylem biogenesis (Szekeres et al., 1996), and bril single mutants and bril brll brl3 triple mutants all displayed severe vascular defects (Cano-Delgado et al., 2004). Furthermore, upon perception of TDIF ligands CLV3 and CLE41, the TDIF receptor (TDR) interacts with BIN2 (Brassinosteroid-Insensitive 2), a member of GSK3 (Glycogen Synthase Kinase 3), to suppress procambial cell differentiation into xylem, which also involves the suppression of BES1 (BRI1-EMS Suppressor 1) downstream of TDR-GSK3 (Kondo et al., 2014; Heo et al., 2017). Given that BAK1 forms a signaling complex with BRI1 and PXY, respectively, it is possible that BAK1 acts as a convergent component shared by the PXY/TDR and BRI1 signaling pathways in $\mathrm{APCD}$ regulation, yet this hypothesis remains to be further investigated and approved.

The BAK1 homologs SERK1 and SERK2 might also play a role in regulating $\mathrm{APCD}$ in anther, in which they interact with the receptor-like kinase EMS1 to perceive the signal of a peptide ligand, TPD1, and control the differentiation of tapetum (Li Z. et al., 2017). Degeneration of tapetum through PCD and the release of its content to nurture maturation of pollen is essential for the success of male reproductive development. In serk1, serk2, or ems 1 mutants, tapetum differentiation and PCD were not properly initiated (Li Z. et al., 2017). This is a scenario similar to that in tracheary element differentiation. Again, a direct link between SERK1/2 and tapetal PCD needs solid experimental support. In the abscission zone, an IDA-HAS/HSL2 signaling pathway also relies on SERK members (SERK1/2/3) to transduce signals for abscission, where PCD is essential (Meng et al., 2016). Whether it is a common theme that BAK1 and other SERKs function upstream of certain dPCDs awaits future studies.

\section{BAK1 in Controlling bPCD Functional Perturbation of BAK1 and Its Partners Triggers bPCD}

BAK1 functions as a co-receptor of multiple RLKs and is involved in diverse signaling pathways. BAKl's function seems essential and is under tight surveillance so that PCD is triggered once its function is perturbed. Previously, a genetic investigation on the single mutation of BAK1 itself and double mutation of BAK1 with its closest homolog BKK1 (SERK4) revealed that while bak1 showed strong premature senescence (Kemmerling et al., 2007; Jeong et al., 2010), cell death in bakl bkk1 double mutants occurs post-embryogenesis, suggesting that BAK1 and BKK1 function redundantly to negatively control cell death (He et al., 2007; de Oliveira et al., 2016). bak1 single mutants developed a type of uncontained PCDs upon infection with virulent necrotrophic pathogens, which differs from both necrotizing elicitor- and SAinducible PCD (Kemmerling et al., 2007). Similarly, silencing BAK1 in $N$. benthamiana also leads to enhanced PCD upon infection with Hyaloperonospora parasitica (Heese et al., 2007).

Interestingly, over-expression of BAK1 or its ectodomain also elicited spontaneous PCD, accumulation of SA and expression of multiple PCD-related genes, including BON1, BIRs, and SOBIR1 (Kim et al., 2017). In line with this finding, constitutive expression of BAK1 or its ectodomain or excess of BAK1 could trigger strong dwarfism and premature death phenotype, as well as autoimmunity without microbe attacks (Domnguez-Ferreras et al., 2015). Therefore, the abundance of BAK1 seems important 
and needs to be kept in check. It is hypothesized that overexpression of BAK1 might sequestrate BIR1 to trigger PCD (Ma et al., 2016). At present, it remains unclear whether bak1/bkk1 cell death is due to the loss of negative regulation of PCD by BAK1 or is caused by an unknown mechanism that monitors developmental defects in bakl.

Multiple signaling components distinct from the BRI1 pathway are also engaged by BAK1 to trigger PCD upon pathogen infection. For instance, a BAK1-interacting RLK, BIR1, was identified by a reverse genetics approach; the bir1-1 mutant displayed extensive cell death and constitutive immunity (Gao et al., 2009). Intriguingly, further suppressor screening using bir1-1 led to the identification of suppressor of bir1-1 (sobir11), which strongly suppressed the cell death observed in bir1-1 (Gao et al., 2009). Moreover, over-expression of SOBIR1 results in elevated cell death, indicating that SOBIR1 functions as a positive regulator of cell death (Gao et al., 2009; Liebrand et al., 2014). Using Co-IP coupled with liquid chromatographyelectrospray ionization-tandem mass spectrometry (LC/ESIMS/MS), two close BIR1 homologs, BIR2 and BIR3, were identified and demonstrated to constitutively interact with, and be phosphorylated by, BAK1, which in turn prevents the formation of the BAK1-FLS2 receptor kinase complex, thus negatively regulating PTI signaling (Halter et al., 2014; Imkampe et al., 2017). Examination of an allelic series of bak1 mutation showed that BIR1 and BAK1 interact genetically to regulate BR signaling, cell death and immune response (Wierzba and Tax, 2016).

bir1 has enhanced SA-dependent PCD (Liu et al., 2016). Moreover, upon infection with a necrotrophic pathogen, Alternaria brassicicola, bir2 mutants had enhanced cell death and susceptibility to this pathogen, whereas BIR2 interacts with BAK1 and suppresses the autoimmune cell death response in the absence of PAMPs (Halter et al., 2014). Furthermore, it was reported that while BIR3 interferes with BRI1-dependent growth by interacting with and stabilizing BAK1, it also negatively affects the formation of the BAK1-FLS2 complex to suppress cell death and immunity, exemplified by the enhanced spontaneous cell death in the bak1 bir3 mutant (Imkampe et al., 2017).

\section{BAK1 Is Involved in Certain PAMP-Triggered PCD}

As a co-receptor of multiple RLKs that perceive PAMPs, BAK1 is required for certain PAMP-triggered PCD; for example, in $N$. benthamiana, triggering of ROS accumulation and HR by the INF1 protein secreted from the oomycete pathogen Phytophthora infestans was prevented by a mutation in BAK1 (Heese et al., 2007; Chaparro-Garcia et al., 2011). A recent study showed that silencing of SOBIR1 in N. benthamiana attenuated INF1triggered cell death and resistance to $P$. infestans, while SOBIR1 was found to form a receptor complex with ELR (Elicitin Response) protein isolated from Solanum microdontum, which is a RLP perceiving INF1 (Domazakis et al., 2018). Moreover, BAK1 is recruited to the ELR/SOBIR1 signaling complex to activate downstream defense response, suggesting that both SOBIR1 and BAK1 are required for INF1-regulated PCD and immunity. Similarly, BcXYG1, a xyloglucanase protein secreted from Botrytis cinerea, interacts with BAK1 and SOBIR1 to trigger cell death and the immune response (Zhu et al., 2017). A small apoplast-targeted cysteine-rich protein, PstSCR1, secreted from the wheat rust pathogen Puccinia striiformis $f$. sp. tritici, triggers PCD and immunity in N. benthamiana via a pathway that appears to be dependent on the BAK1 pathway (Dagvadorj et al., 2017).

Moreover, BAK1 cooperates with SOBIR1 and RLP30 (Receptor-Like Protein 30) to control PCD caused by necrotrophic pathogens. RLP30 is responsible for the sensitivity to SCLEROTINIA CULTURE FILTRATE ELICITOR1 (SCFE1)containing fraction, which contains a proteinaceous elicitor, produced by S. sclerotiorum, and rlp30 mutants showed increased cell death and susceptibility to infection with necrotrophic pathogens S. sclerotiorum and B. cinerea (Zhang et al., 2013). In addition, BAK1 was found to interact with one of the LRR-RLP receptors in $N$. benthamiana, LeEix1, to attenuate the LeEix2mediated Eix (Ethylene-inducing xylanase) response in tobacco (Nicotiana tabacum) and tomato (Solanum lycopersicum) in order to trigger the typical HR response (Bar et al., 2010).

Using proteomic approaches several RLKs, cysteine-rich receptor-like kinases (CRKs) enriched at the plasma membrane, were identified while the expression levels of these CRKs were activated upon the ligand elicitation of flagellin in Arabidopsis (Yadeta et al., 2017). Among those CRKs, the induction of CRK28 activity was highly correlated with enhanced resistance to the wheat rust pathogen $P$. striiformis $f$. sp. tritici and increased ROS production; moreover, the kinase active site of CRK28 (K377) is required for triggering cell death. CRK28 associates with the FLS2/BAK1 immune complex in a flg22-dependent manner, and CRK28-induced cell death was abolished in NbSerk3-silenced $N$. benthamiana plants, suggesting that BAK1 is required for CRK28-mediated cell death (Yadeta et al., 2017).

However, in some cases, loss of BAK1 function enhances the cell death triggered by PAMPs or DAMPs. A recent study showed that when PTI signaling is compromised by BAK1 disruption, danger peptide receptor PEPRs (Pep Receptors) signaling could be activated to ensure basal resistance. Depletion of BAK1 sensitized PEPRs signaling toward cell death upon ligand elicitation, as the ligand Pep2 was found to induce extensive cell death in bak1-4 mutants, which is dependent on PEPRs (Yamada et al., 2016). It is believed that such an enhanced PCD phenotype in bak1 mutant upon pathogen infection is caused by the subsequent dysfunction of BAK1/BON1 suppressed cell death, which in turn activates the PEPR signaling pathway to reversely trigger cell death and to retain immunity to biotrophic pathogens (Yamada et al., 2016).

\section{BAK1 and Effector Triggered PCD}

Lines of evidence suggest that PCD triggered by perturbation of BAK1 functions shows similarity to R-protein-mediated PCD. SALICYLIC ACID INDUCTION-DEFICIENT (SID2) and ENHANCED DISEASE SUSCEPTIBILITY5 (EDS5), two chloroplast-localized components of the salicylic acid (SA)mediated ETI pathway, were also proposed to contribute to cell death by BAK1/BKK1 mutations, thereby regulating PCD; the sid2 and eds 5 mutations suppress cell death in bak1-3bkk11 mutants, and this cell death is dependent on light and 
SA (Gao et al., 2017). In line with this finding, the overexpression of BAK1 resulted in the accumulation of SA and hydrogen peroxide, as well as the enhanced expression of $B O N 1, B I R s$, and SOBIR, the processes strongly associated with spontaneous cell death (Kim et al., 2017). BON1, functioning as a negative regulator of $\mathrm{R}$-mediated resistance, interacts with both BAK1 and BIR1 to interfere with the immune response and PCD (Wang et al., 2011). Furthermore, enhanced cell death in birl plants was found to be partially dependent on PHYTOALEXIN DEFICIENT4 (PAD4) and EDS1, which is required for TIR NLR signaling. This suggests that BIR1 might be guarded by plant resistance ( $R$ ) protein signaling (Gao et al., 2009).

BAK1 seems also to participate in other PCDs during ETI. Two effectors from the tomato pathogen Cladosporium fulvum, Avr4 and Avr9, are recognized by the R proteins Cf4 and Cf-9, respectively, which in turn recruit BAK1 and subsequently trigger the $\mathrm{HR}$ and immunity against $C$. fulvum (Postma et al., 2016). The BAK1/SOBIR1-dependent pathway was also shown to mediate the interaction between the tomato resistance gene I, a LRR-RLP involved in the immunity to Fusarium oxysporum f. sp. lycopersici (Fol), and the FolAvr1 effector, triggering necrosis in $N$. benthamiana (Catanzariti et al., 2017). Moreover, BAK1 positively regulates the NLR protein $\mathrm{Mi}-1$ in resistance and cell death upon potato aphid infection in the tomato (Peng and Kaloshian, 2014; Peng et al., 2016).

\section{POSSIBLE MECHANISMS UNDERLYING CONTRADICTORY FUNCTION OF BAK1 IN PCD}

As reviewed above, BAK1 is involved in different forms of PCDs. However, it is intriguing that BAK1 could serve as both positive and negative regulators of PCDs. The question about how BAK1, as a single RLK, is capable of controlling different PCD processes oppositely remains open to answer. Here, we would like to summarize the possible molecular mechanisms that might explain the complicated function of BAK1 in PCD.

It is possible that the output specificity of BAK1 functions in different PCD processes is determined by the ligand specificity of corresponding RLKs. Therefore, the effects of disrupted BAK1 functioning are likely dependent on the role of BAK1 in that specific complex. BAK1 also interacts with other RLKs including BIR1, BIR2, and SOBIR1. The balance between different BAK1-incorporated complexes is obviously influenced by the abundance of BAK1. These interacting RLKs might keep each other under tight control to ensure proper activation of PCDs. It has been shown that both BIR1 and BIR2 appear to be essential in structurally keeping BAK1-regulated PCD under tight control in the case of no ligand binding, thus interfering the unwanted interaction between BAK1 and different PRRs (Ma et al., 2017). Moreover, a specific ligand stimulates the release of BIR2-sequestered BAK1, which subsequently enhances the interaction complex formation between BAK1 and PRR, FLS2, EFR, BRI1, PEPR1, etc., (Halter et al., 2014). Interestingly, BIR1,
BIR3, and BIR4 all formed a stable heterodimeric complex with BAK1 at pH 6.0 through their ecto-domains, and flg22bound FLS2 outcompeted BIR $1^{\mathrm{LRR}}$ for binding to BAK1 ${ }^{\mathrm{LRR}}$ (Ma et al., 2017). On the other hand, upon pathogen infection, bak1bir3 showed increased pathogen-inducible PCD (Imkampe et al., 2017); upon ligand perception, overexpression of BIR2 suppressed the BAK1/FLS2 (PRR) complex formation (Halter et al., 2014). Moreover, BAK1 overexpression results in runaway cell death, and simultaneous overexpression of BRI1 and BAK1 suppresses this cell death, suggesting that activation of the BAK1PRR signaling complex upon ligand binding is essential to suppress this type of auto-immune PCD (Belkhadir et al., 2012; Halter et al., 2014).

The downstream signaling events upon activation of PRRBAK1 complexes also show specificity to ligands. A very recent study suggests that the specificity might be determined by the phosphosite code in BAK1. They identified multiple BAK1 phosphosites specific to the signaling processes, e.g., immunity or growth, but not others (Perraki et al., 2018). In this case, the mutation of multiple key phosphorylation sites in BAK1, including S602D/T603D/S604D or S612D, resulted in impaired PTI responses, including flg22-induced MAPK signaling and immunity to Pst DC3000, but dispensable for BR-signaling. Moreover, the mutation of Y403 in the BAK1 C-terminal attenuated the phosphorylation and BAK/EFR signaling complex formation upon elf18 elicitation (Perraki et al., 2018). Other studies also support that the intracellular domains have separable functions in mediating different signaling processes. In a birl suppressor screen using bir1-1pad4-1 mutant, sobir7-1, a bak1 allele with a nonsense mutation within the carboxyl-terminal tail (CT) of BAK1, was identified (Liu et al., 2016; Wu et al., 2018). A series of genetic evidence proved that the CT domain of BAK1 was essential for its kinase activity to trigger PTI response, but dispensable for controlling cell death and BR signaling (Liu et al., 2016; Wu et al., 2018). It is worth investigating how the differential regulation of PCD involving BAK1 might also attribute to the diverse phosphosite codes activated.

As discussed above, the PCD triggered by disruption of BAK1 might be mediated by certain $R$ proteins, which is a well-accepted theme that host protein is guarded by cognate $\mathrm{R}$ proteins. If this is true, the cell death caused by BAK1/BKK1 loss-of-function does not imply they are negative regulators of PCD, but instead that they are such important signaling components that their disruption is monitored by R-protein. Some cases whereby $\mathrm{R}$ proteins guard important host signaling components have been reported. For example, RIN4 is guarded by two NLRs, RPM1 and RPS2, and disruption of the MAP kinase cascade, MEKK1/MKK5/MPK4, will trigger the activation of SUMM2 R-protein and cell death (Zhang et al., 2012). Moreover, PAD4-dependent immunity is activated in bir1-1, raising the possibility that BIR1 is guarded by $\mathrm{R}$ gene, too (Liu et al., 2016). Indeed, it has been proposed that BAK1/BIR1 is probably guarded by two or more $\mathrm{R}$ proteins in the absence of pathogens. Mutation of BAK1 or BIR1 results in the activation of those guard $\mathrm{R}$ proteins, which subsequently trigger different signaling pathways, e.g., disease resistance and/or PCD, mediated by PAD4 and SOBIR1, respectively, (Gao et al., 2009). In 
line with this finding, SRF3, an LRR-RLK structurally similar to BIR2, has been reported to regulate hybrid incompatibility along with the $\mathrm{R}$ gene $R P P 1$, during which necrotic PCD, enhanced SA levels and immune response were found. This illustrates a model that SRF3 is guarded by RPP1 to control incompatibility in the absence of pathogens (Alcazar et al., 2010).

Nevertheless, as a center component involved in various signaling pathways, it appears that an optimal amount of BAK1 should be strictly maintained to optimize the fitness of growth/development and disease resistance/PCD. While being tightly guarded by and released from R proteins, and responding to appropriate ligands to interact selectively with different PRRs, BAK1 has evolved multiple strategies to cooperate with diverse signaling components to fine-tune its function in regulating different types of PCD.

\section{REGULATION OF BAK1-MEDIATED PCD}

Several studies have suggested that the perception of PAMPs by the PRRs and the subsequent activation of downstream signaling are associated with multiple regulation events, especially PTMs (such as phosphorylation, ubiquitination, glycosylation), and protein endocytosis ( $\mathrm{Lu}$ et al., 2011; Kadota et al., 2014; Lin et al., 2014). The importance of some of these processes has also been demonstrated to be associated with the functional dynamics of BAK1mediated PCD (Bender et al., 2015; de Oliveira et al., 2016; Table 1).

As discussed above, BAK1 signaling specificity might be determined by the code of phosphosites (Perraki et al., 2018). The phosphorylation of non-RD plasma membrane-localized LRR-RKs, including FLS2 and EFR, by BAK1 is essential for inducing PTI upon the perception of PAMPs, which is different from that of RD-kinase BRI1 phosphorylation by BAK1 (Schulze et al., 2010; Schwessinger et al., 2011). In this case, the bak1-5 mutant, a novel mutant $B A K 1$ allele carrying a single amino acid substitution, C408Y, in the BAK1 cytoplasmic kinase domain, is impaired in PTI signaling but not in cell death regulation. Upon ligand elicitation, however, BAK1-5 kinase activity is required for the formation of BAK1/FLS2 or BAK1/EFR PRR complexes. Moreover, the bak1-5 line becomes insensitive to SCFE1, and did not show enhanced PCD. This was different from bak13 and bak1-4 mutants, which are susceptible to B. cinerea and A. brassicicola (Kemmerling et al., 2007). These findings strongly support the mechanistically uncoupled and phosphorylationdependent activation function for BAK1 in regulating distinct signaling pathways, e.g., BR-associated development, PCD and PTI responses (Schwessinger et al., 2011; Monaghan and Zipfel, 2012).

BAK1 is also capable of phosphorylating BIK1 at tyrosine and serine/threonine sites, as evidenced by the requirement for kinase activity and the presence of three tyrosine residues (Y150, Y243, and Y250) in BIK1 for its function in immunity (Lin et al., 2014). Furthermore, upon PAMP elicitation, BIK1 could directly interact with and phosphorylate RBOHD to control the
ROS burst and promote resistance to bacterial pathogens (Kadota et al., 2014).

In addition to phosphorylation, other PTM processes participate in the regulation of BAK1 activity. For instance, the PAMP flg22 triggers the recruitment of a pair of plant U-box E3 ligases, PUB12 and PUB13, to FLS2, which is subsequently degraded by ubiquitination. Interestingly, FLS2 ubiquitination by PUB12/13 requires the BAK1-mediated phosphorylation of FLS2 (Lu et al., 2011). Since it has been shown that disruption of PUB13 caused a spontaneous cell death phenotype, which was also enhanced under high humidity conditions (Li W. et al., 2012), it is reasonable to speculate that an ubiquitination event might also be involved in BAK1-mediated PCD.

Using the BAK1 cytoplasmic domain as bait to screen a yeast two-hybrid library, a glutaredoxin (GRX) C2 (AtGRXC2) protein was characterized to be a BAK1-interacting component. AtGRXC2 can $S$-glutathionylate and form a heterodimer with the BAK1 cytoplasmic domain in vitro in the presence of either glutathione disulfide or glutathione plus $\mathrm{H}_{2} \mathrm{O}_{2}$, thus inhibiting BAK1 kinase activity (Bender et al., 2015). BAK1 kinase activity was enhanced by the mutation of an AtGRXC2-targeted essential glutathionylation site, Cys408 to tyrosine, in a bak1-5 background (Bender et al., 2015). Although it remains to be determined whether BAK1 glutathionylation is directly associated with its role in the regulation of PCD and immunity, this finding reveals a novel regulatory mechanism of BAK1 signaling by redox status and glutathionylation.

The process of endoplasmic reticulum (ER)-mediated protein quality control (ERQC) and glycosylation were shown to be important for BAK1-mediated PCD as well. To identify the suppressor of cell death that silences BAK1/SERK4 (BKK1) and BIR1, a virus-induced gene silencing (VIGS)-based genetic screen was carried out in the bak1-4serk4-1 and birl mutant backgrounds, leading to the identification of a mutant with a defective STAUROSPORIN AND TEMPERATURE SENSITIVE3 (STT3a) protein (de Oliveira et al., 2016). The stt3a-2 mutation significantly suppresses cell death, $\mathrm{H}_{2} \mathrm{O}_{2}$ accumulation, and PR1 and PR2 expression in the bak1-4serk4-1 and bir1 backgrounds, providing strong genetic evidence for the positive role of STT3a in triggering PCD and the immune response (de Oliveira et al., 2016). Interestingly, several specific ERQC components, such as ERdj3b and SDF2, seem to be involved in triggering cell death in the bak1-4/serk4-1 mutants (Sun et al., 2014). On the other hand, using an RNA-seq analysis, one of the most highly activated gene families in bak1-4/serk4-1 was found to be the CRKs, including CRK4 and CRK5, which strongly elicit cell death when transiently overexpressed in N. benthamiana (de Oliveira et al., 2016). Moreover, a biochemical analysis showed that CRK4 and CRK5 are likely the targets of glycosylation, as revealed by an obvious migration shift under electrophoresis. Given the known function of STT3 as a catalytic subunit of oligosaccharyltransferase in protein $\mathrm{N}$-glycosylation, these findings suggest that STT3amediated $\mathrm{N}$-glycosylation and ERQC are essential for CRK4mediated PCD. It remains to be determined whether CRK4 and CRK5 are necessary and sufficient for the cell death in bak14 serk4-1 mutant plants (de Oliveira et al., 2016). This result is further supported by the finding that CRK28 is also a glycosylated 
transmembrane protein found in a PRR-RLK complex (Yadeta et al., 2017). Intriguingly, it is noted that a subset of LRR-RK-type PRRs, including EFR and Xa21, specifically require this ERQC pathway in their proper folding and maturation (Saijo, 2010; Beck et al., 2012), implying the possible recruitment of a similar LRR-RK to mediate cell death in the absence of BAK1.

In addition to the aforementioned ERQC pathway and glycosylation, nucleocytoplasmic trafficking is also essential to BAK1-mediated PCD. sbb1-1, another suppressor of cell death in bak1-4 serk4-1, was identified in a genetic screen (Du et al., 2016). SBB1 encodes a nucleoporin (NUP) 85-like protein that is a member of the NUP107-160 sub-complex, the largest subcomplex known to be highly conserved in vertebrates and plants. Knocking out individual NUP members including SBB1 (NUP85), SEH1, NUP160, or NUP96 fully suppresses the cell death phenotype of the bak1-4 and serk4-1 mutants. The sbb1 mutation reduced endogenous SA levels and the $s b b 1$ mutant suppressed cell death in bak1-4 and serk4-1, and expression of $S B B 1$ driven by its own promoter in bak1-3 bkk1-1 sbb1-2 can recapitulate cell death phenotype, suggesting that SBB1mediated cell death in bak1-4serk4-1 is SA-dependent (Du et al., 2016). Interestingly, co-immunoprecipitation coupled with LC-MS/MS analyses identified numerous SBB1-interacting proteins, including DEAD-box RNA helicase 1 (DRH1), which was found to directly associate with SBB1. Genetic data demonstrated that SBB1-DRH1 is required for cell death in bak1-4 and serk4-1. Consistent with the observation that DRH1 is localized at the nucleus and that SBB1 functions in mRNA export, the SBB1-DRH1 complex-mediated nucleocytoplasmic trafficking process likely contributes to BAK1/SERK4-controlled cell death, which might be exerted through its interference in the export of SA-related mRNAs (Du et al., 2016).

Endocytosis is also involved in BAK1-mediated PCD. For example, interaction of BAK1 with LeEixl results in the endocytosis of LeEix2, whereas LeEix1 interferes with the LeEix2triggered immune response and $\mathrm{HR}$, which was impaired in the BAK1-silenced plants (Bar et al., 2010). This finding reveals the key role of BAK1 in regulating Eix-induced PCD and the PTM of the LRR-RLP receptor upon pathogen infection.

\section{CONCLUSION AND PERSPECTIVES}

Cell death is an essential process for both mammals and plants. Despite the remarkable progress made in the elucidation of the occurrence and features of PCD, more research is needed to determine how host plants perceive and transduce external signals to activate PCD. Similar to animals, PCD is deployed by plants to facilitate cell differentiation during development or to promote survival by enabling plants to adapt to environmental stresses and defend against pathogens. Accumulating evidence points to the central role of BAK1 as a co-receptor or signaling regulator of multiple receptor kinases and RLPs in different types of PCD. BAK1 likely exerts its function via deploying its specific phosphorylation sites to phosphorylate PCD-related RLKs or RLPs (Perraki et al., 2018), differentiating responses to the elicitation by various ligand bindings, and to distinctly modulate PCD.

BAK1 has been intensively investigated for its function as the key component of the BR-mediated signaling pathway and the RLK-mediated PTI signaling pathway; thus, it is reasonable to theorize that $\mathrm{APCD}$ (meristem cell death) and bPCD converge at BAK1. It has been proposed that calcium signaling (for example, via the CDPKs) (Boursiac et al., 2010; Gao et al., 2013a) and ROS production are involved in the regulation of both $\mathrm{APCD}$ and bPCD (Gechev and Hille, 2005; Boursiac et al., 2010; Petrov et al., 2015; Serrano et al., 2015). Given the pivotal role of BAK1 as a co-receptor of the PTI signaling complex in triggering PCD, it is tempting to speculate that BAK1 may function upstream of ROS and/or calcium signaling to regulate the diverse types of PCD, probably through the activation of a MAPK signaling cascade $(\mathrm{He}$ et al., 2007; Kemmerling et al., 2007; Jeworutzki et al., 2010; Gao et al., 2013b).

PCD is considered to be a hallmark of the ETI response. Upon ETI activation, PCD can also be triggered via CDPK-mediated signaling, likely through the phosphorylation of specific WRKY transcription factors (Gao et al., 2013a); however, it is unclear whether BAK1 exerts its negative role in controlling PCD as either a shared core regulator of ETI-triggered PCD or through distinct mechanisms. There is accumulating evidence to suggest that BAK1 could be targeted by multiple effectors (Macho and Zipfel, 2014); for instance, by AvrPtoB (Shan et al., 2008) and HopF2 (Zhou et al., 2014) from Pseudomonas syringae, and Avr3a from P. infestans (Chaparro-Garcia et al., 2011), resulting in disruption of PTI signaling as well as that of PCD suppressed by BAK1. Furthermore, SOBIR1 associates with or interacts with several R proteins (Qi et al., 2011; Ma and Borhan, 2015); thus, it is possible that activation of ETI-associated PCD might be attributed, at least to some extent, to the negative regulation by BAK1 and BAK1/SOBIR1 receptor complexes. One should be cautious, however, that BAK1 targeting by different effectors leading to enhanced cell death may not be pertinent to all forms of BAK1. This is because BAK1-5 is a hypoactive kinase and the bak1-5 mutant is not impaired in cell death control (Schwessinger et al., 2011), whereas the kinase domain of BAK1 seems to be essential for AvrPtoB targeting structurally (Cheng et al., 2011).

PCD functions at essential steps in development and aging as well as in abiotic and biotic stresses. It seems that plants may deploy the BAK1 signaling complex to coordinate different types of PCD and thus control the trade-off between development and immunity, possibly via subverting hormone signaling, interacting with R proteins, and integrating distinct PTM processes. Future research should center on exploring how host plants control PCD by orchestrating BAK1 homeostasis, which may also provide practical implications for crop improvement. Moreover, despite the fact that animal apoptosis-like cell death has not been fully addressed in plants, recent evidence has suggested the presence and functional importance of animal-type apoptosis in plant PCD (Dickman et al., 2017). Another research direction will therefore involve clarification of the relationship between BAK1regulated PCD and apoptosis-like cell death, as well as other cell death processes, such as autophagy, under different stresses or environmental stimuli. 


\section{AUTHOR CONTRIBUTIONS}

$\mathrm{XG}$ wrote the manuscript. XG and $\mathrm{BF}$ revised the manuscript with input from XR, YS and XW.

\section{FUNDING}

We are grateful for financial support in the form of grants from the National Key Research and Development Program of China (No. 2016YFD0101002), the NSFC (Nos. 31471508 and 31671702), the Technology Foundation for Selected

\section{REFERENCES}

Aan den Toorn, M., Albrecht, C., and de Vries, S. (2015). On the origin of SERKs: bioinformatics analysis of the somatic embryogenesis receptor kinases. Mol. Plant 8, 762-782. doi: 10.1016/j.molp.2015.03.015

Affenzeller, M. J., Darehshouri, A., Andosch, A., Lutz, C., and LutzMeindl, U. (2009). Salt stress-induced cell death in the unicellular green alga Micrasterias denticulata. J. Exp. Bot. 60, 939-954.doi: 10.1093/jxb/ ern348

Albert, I., Bohm, H., Albert, M., Feiler, C. E., Imkampe, J., Wallmeroth, N., et al. (2015). An RLP23-SOBIR1-BAK1 complex mediates NLP-triggered immunity. Nat. Plants 1:15140. doi: 10.1038/nplants.2015.140

Alcazar, R., Garcia, A. V., Kronholm, I., de Meaux, J., Koornneef, M., Parker, J. E., et al. (2010). Natural variation at strubbelig receptor kinase 3 drives immunetriggered incompatibilities between Arabidopsis thaliana accessions. Nat. Genet. 42, 1135-1139. doi: 10.1038/ng.704

Ameisen, J. C. (2002). On the origin, evolution, and nature of programmed cell death: a timeline of four billion years. Cell Death Differ. 9, 367-393. doi: 10 1038/sj.cdd.4400950

Asami, T., Min, Y. K., Nagata, N., Yamagishi, K., Takatsuto, S., Fujioka, S., et al (2000). Characterization of brassinazole, a triazole-type brassinosteroid biosynthesis inhibitor. Plant Physiol. 123, 93-100. doi: 10.1104/pp. 123.1.93

Avci, U., Petzold, H. E., Ismail, I. O., Beers, E. P., and Haigler, C. H. (2008). Cysteine proteases XCP1 and XCP2 aid micro-autolysis within the intact central vacuole during xylogenesis in Arabidopsis roots. Plant J. 56, 303-315. doi: 10.1111/j. 1365-313X.2008.03592.x

Bar, M., Sharfman, M., Ron, M., and Avni, A. (2010). BAK1 is required for the attenuation of ethylene-inducing xylanase (Eix)-induced defense responses by the decoy receptor LeEix1. Plant J. 63, 791-800. doi: 10.1111/j.1365-313X.2010. 04282.x

Baudino, S., Hansen, S., Brettschneider, R., Hecht, V. F., Dresselhaus, T., Lörz, H., et al. (2001). Molecular characterisation of two novel maize LRR receptorlike kinases, which belong to the SERK gene family. Planta 213, 1-10. doi: $10.1007 / \mathrm{s} 004250000471$

Beck, M., Heard, W., Mbengue, M., and Robatzek, S. (2012). The INs and OUTs of pattern recognition receptors at the cell surface. Curr. Opin. Plant Biol. 15 , 367-374. doi: 10.1016/j.pbi.2012.05.004

Beers, E. P. (1997). Programmed cell death during plant growth and development Cell Death Differ. 4, 649-661. doi: 10.1038/sj.cdd.4400297

Belkhadir, Y., Jaillais, Y., Epple, P., Balsemao-Pires, E., Dangl, J. L., and Chory, J. (2012). Brassinosteroids modulate the efficiency of plant immune responses to microbe-associated molecular patterns. Proc. Natl. Acad. Sci. U.S.A. 109, 297-302. doi: 10.1073/pnas.11128 40108

Bender, K. W., Wang, X., Cheng, G. B., Kim, H. S., Zielinski, R. E., and Huber S. C. (2015). Glutaredoxin AtGRXC2 catalyses inhibitory glutathionylation of Arabidopsis BRI1-associated receptor-like kinase 1 (BAK1) in vitro. Biochem. J. 467, 399-413. doi: 10.1042/BJ20141403

Berry, D. L., and Baehrecke, E. H. (2008). Autophagy functions in programmed cell death. Autophagy 4, 359-360. doi: 10.4161/auto.5575
Overseas Chinese Scholar, Ministry of Personnel of China (No. G0101500090), and from the Jiangsu Collaborative Innovation Center for Modern Crop Production (JCIC-MCP) and the Innovation Team Program for Jiangsu Universities (2014).

\section{ACKNOWLEDGMENTS}

We apologize to the many authors whose significant works are not cited here due to space limitations. We acknowledge Dr. Michael V. Kolomiets and Dr. Dongping Lu for their critical review of this manuscript and their insightful discussion.

Bigeard, J., Colcombet, J., and Hirt, H. (2015). Signaling mechanisms in patterntriggered immunity (PTI). Mol. Plant 8, 521-539. doi: 10.1016/j.molp.2014.12. 022

Bollhoner, B., Zhang, B., Stael, S., Denance, N., Overmyer, K., Goffner, D., et al. (2013). Post mortem function of AtMC9 in xylem vessel elements. New Phytol. 200, 498-510. doi: 10.1111/nph.12387

Boursiac, Y., Lee, S. M., Romanowsky, S., Blank, R., Sladek, C., Chung, W. S., et al. (2010). Disruption of the vacuolar calcium-ATPases in Arabidopsis results in the activation of a salicylic acid-dependent programmed cell death pathway. Plant Physiol. 154, 1158-1171. doi: 10.1104/pp.110.15 9038

Bozhkov, P. V., Filonova, L. H., and Suarez, M. F. (2005). Programmed cell death in plant embryogenesis. Curr. Top. Dev. Biol. 67, 135-179. doi: 10.1016/S00702153(05)67004-4

Cano-Delgado, A., Yin, Y. H., Yu, C., Vafeados, D., Mora-Garcia, S., Cheng, J. C., et al. (2004). BRL1 and BRL3 are novel brassinosteroid receptors that function in vascular differentiation in Arabidopsis. Development 131, 5341-5351. doi: 10.1242/dev.01403

Caplan, J., Padmanabhan, M., and Dinesh-Kumar, S. P. (2008). Plant NB-LRR immune receptors: from recognition to transcriptional reprogramming. Cell Host Microbe 3, 126-135. doi: 10.1016/j.chom.2008.02.010

Catanzariti, A. M., Do, H. T., Bru, P., de Sain, M., Thatcher, L. F., Rep, M., et al. (2017). The tomato I gene for Fusarium wilt resistance encodes an atypical leucine-rich repeat receptor-like protein whose function is nevertheless dependent on SOBIR1 and SERK3/BAK1. Plant J. 89, 1195-1209. doi: 10.1111/ tpj. 13458

Chaparro-Garcia, A., Wilkinson, R. C., Gimenez-Ibanez, S., Findlay, K., Coffey, M. D., Zipfel, C., et al. (2011). The receptor-like kinase SERK3/BAK1 is required for basal resistance against the late blight pathogen phytophthora infestans in Nicotiana benthamiana. PLoS One 6:e16608. doi: 10.1371/journal.pone.001 6608

Cheng, W., Munkvold, K. R., Gao, H., Mathieu, J., Schwizer, S., Wang, S., et al. (2011). Structural analysis of Pseudomonas syringae AvrPtoB bound to host BAK1 reveals two similar kinase-interacting domains in a type III effector. Cell Host Microbe 10, 616-626. doi: 10.1016/j.chom.2011. 10.013

Chinchilla, D., Bauer, Z., Regenass, M., Boller, T., and Felix, G. (2006). The Arabidopsis receptor kinase FLS2 binds flg22 and determines the specificity of flagellin perception. Plant Cell 18, 465-476. doi: 10.1105/tpc.105.036574

Chinchilla, D., Shan, L., He, P., de Vries, S., and Kemmerling, B. (2009). One for all: the receptor-associated kinase BAK1. Trends Plant Sci. 14, 535-541. doi: 10.1016/j.tplants.2009.08.002

Chinchilla, D., Zipfel, C., Robatzek, S., Kemmerling, B., Nurnberger, T., Jones, J. D., et al. (2007). A flagellin-induced complex of the receptor FLS2 and BAK1 initiates plant defence. Nature 448, 497-500. doi: 10.1038/nature 05999

Coll, N. S., Epple, P., and Dangl, J. L. (2011). Programmed cell death in the plant immune system. Cell Death Differ. 18, 1247-1256. doi: 10.1038/cdd.2011.37

Dagvadorj, B., Ozketen, A. C., Andac, A., Duggan, C., Bozkurt, T. O., and Akkaya, M. S. (2017). A Puccinia striiformis f. sp tritici secreted protein activates plant immunity at the cell surface. Sci. Rep. 7:1141. doi: 10.1038/s41598-017-01100-z 
Daneva, A., Gao, Z., Van Durme, M., and Nowack, M. K. (2016). Functions and regulation of programmed cell death in plant development. Annu. Rev. Cell Dev. Biol. 32, 441-468. doi: 10.1146/annurev-cellbio-111315-124915

Danon, A., Delorme, V., Mailhac, N., and Gallois, P. (2000). Plant programmed cell death: a common way to die. Plant Physiol. Biochem. 38, 647-655. doi: 10.1016/S0981-9428(00)01178-5

Dardick, C., Schwessinger, B., and Ronald, P. (2012). Non-arginine-aspartate (non-RD) kinases are associated with innate immune receptors that recognize conserved microbial signatures. Curr. Opin. Plant Biol. 15, 358-366. doi: 10. 1016/j.pbi.2012.05.002

de Oliveira, M. V., Xu, G., Li, B., de Souza Vespoli, L., Meng, X., Chen, X., et al. (2016). Specific control of Arabidopsis BAK1/SERK4-regulated cell death by protein glycosylation. Nat. Plants 2:15218. doi: 10.1038/nplants. 2015.218

Dickman, M., Williams, B., Li, Y., de Figueiredo, P., and Wolpert, T. (2017). Reassessing apoptosis in plants. Nat. Plants 3, 773-779. doi: 10.1038/s41477017-0020-x

Domazakis, E., Wouters, D., Visser, R. G. F., Kamoun, S., Joosten, M. H. A. J., and Vleeshouwers, V. G. A. A. (2018). The ELR-SOBIR1 complex functions as a two-component receptor-like kinase to mount defense against phytophthora infestans. Mol. Plant Microbe Interact. 31, 795-802. doi: 10.1094/MPMI-09-170217-R

Domnguez-Ferreras, A., Kiss-Papp, M., Jehle, A. K., Felix, G., and Chinchilla, D. (2015). An overdose of the Arabidopsis coreceptor BRASSINOSTEROID INSENSITIVE1-ASSOCIATED RECEPTOR KINASE1 or its ectodomain causes autoimmunity in a SUPPRESSOR OF BIR1-1-dependent manner. Plant Physiol. 168, 1106-1121. doi: 10.1104/pp.15.00537

Du, J., Gao, Y., Zhan, Y., Zhang, S., Wu, Y., Xiao, Y., et al. (2016). Nucleocytoplasmic trafficking is essential for BAK1- and BKK1-mediated celldeath control. Plant J. 85, 520-531. doi: 10.1111/tpj.13125

Duan, Y. F., Zhang, W. S., Li, B., Wang, Y. N., Li, K. X., Sodmergen et al. (2010). An endoplasmic reticulum response pathway mediates programmed cell death of root tip induced by water stress in Arabidopsis. New Phytol. 186, 681-695. doi: $10.1111 /$ j.1469-8137.2010.03207.x

Eitas, T. K., and Dangl, J. L. (2010). NB-LRR proteins: pairs, pieces, perception, partners, and pathways. Curr. Opin. Plant Biol. 13, 472-477. doi: 10.1016/j.pbi. 2010.04.007

Farber, E. (1994). Programmed cell death: necrosis versus apoptosis. Mod. Pathol. 7, 605-609.

Fath, A., Bethke, P., Lonsdale, J., Meza-Romero, R., and Jones, R. (2000). Programmed cell death in cereal aleurone. Plant Mol. Biol. 44, 255-266. doi: 10.1023/A:1026584207243

Feng, F., and Zhou, J. M. (2012). Plant-bacterial pathogen interactions mediated by type III effectors. Curr. Opin. Plant Biol. 15, 469-476. doi: 10.1016/j.pbi.2012.03. 004

Fukuda, H. (1997). Tracheary element differentiation. Plant Cell 9, 1147-1156. doi: 10.1105/tpc.9.7.1147

Fukuda, H. (2000). Programmed cell death of tracheary elements as a paradigm in plants. Plant Mol. Biol. 44, 245-253. doi: 10.1023/A:1026532223173

Gao, M., Wang, X., Wang, D., Xu, F., Ding, X., Zhang, Z., et al. (2009). Regulation of cell death and innate immunity by two receptor-like kinases in Arabidopsis. Cell Host Microbe 6, 34-44. doi: 10.1016/j.chom.2009. 05.019

Gao, X., Chen, X., Lin, W., Chen, S., Lu, D., Niu, Y., et al. (2013a). Bifurcation of Arabidopsis NLR immune signaling via $\mathrm{Ca}(2)(+)$-dependent protein kinases. PLoS Pathog. 9:e1003127. doi: 10.1371/journal.ppat.1003127

Gao, X., Li, F. J., Li, M. Y., Kianinejad, A. S., Dever, J. K., Wheeler, T. A., et al. (2013b). Cotton GhBAK1 mediates verticillium wilt resistance and cell death. J. Integr. Plant Biol. 55, 586-596. doi: 10.1111/jipb. 12064

Gao, Y., Wu, Y., Du, J., Zhan, Y., Sun, D., Zhao, J., et al. (2017). Both lightinduced SA accumulation and ETI mediators contribute to the cell death regulated by BAK1 and BKK1. Front. Plant Sci. 8:622. doi: 10.3389/fpls.2017. 00622

Gechev, T. S., and Hille, J. (2005). Hydrogen peroxide as a signal controlling plant programmed cell death. J. Cell Biol. 168, 17-20. doi: 10.1083/jcb.200409170

Gepstein, S., and Glick, B. R. (2013). Strategies to ameliorate abiotic stress-induced plant senescence. Plant Mol. Biol. 82, 623-633. doi: 10.1007/s11103-013-0038-z
Gomez-Gomez, L., and Boller, T. (2000). FLS2: an LRR receptor-like kinase involved in the perception of the bacterial elicitor flagellin in Arabidopsis. Mol. Cell 5, 1003-1011. doi: 10.1016/S1097-2765(00)80265-8

Greenberg, J. T. (1996). Programmed cell death: a way of life for plants. Proc. Natl. Acad. Sci. U.S.A. 93, 12094-12097. doi: 10.1073/pnas.93.22.12094

Greenberg, J. T. (1997). Programmed cell death in plant-pathogen interactions. Annu. Rev. Plant Physiol. Plant Mol. Biol. 48, 525-545. doi: 10.1146/annurev. arplant.48.1.525

Halter, T., Imkampe, J., Mazzotta, S., Wierzba, M., Postel, S., Bücherl, C., et al. (2014). The leucine-rich repeat receptor kinase BIR2 is a negative regulator of BAK1 in plant immunity. Curr. Biol. 24, 134-143. doi: 10.1016/j.cub.2013.11. 047

Hameed, A., Goher, M., and Iqbal, N. (2013). Drought induced programmed cell death and associated changes in antioxidants, proteases, and lipid peroxidation in wheat leaves. Biol. Plant. 57, 370-374. doi: 10.1007/s10535-012-0286-9

He, K., Gou, X., Yuan, T., Lin, H., Asami, T., Yoshida, S., et al. (2007). BAK1 and BKK1 regulate brassinosteroid-dependent growth and brassinosteroidindependent cell-death pathways. Curr. Biol. 17, 1109-1115. doi: 10.1016/j.cub. 2007.05.036

Heese, A., Hann, D. R., Gimenez-Ibanez, S., Jones, A. M., He, K., Li, J., et al. (2007). The receptor-like kinase SERK3/BAK1 is a central regulator of innate immunity in plants. Proc. Natl. Acad. Sci. U.S.A. 104, 12217-12222. doi: 10.1073/pnas. 0705306104

Heller, J., Clave, C., Gladieux, P., Saupe, S. J., and Glass, N. L. (2018). NLR surveillance of essential SEC-9 SNARE proteins induces programmed cell death upon allorecognition in filamentous fungi. Proc. Natl. Acad. Sci. U.S.A. 115, E2292-E2301. doi: 10.1073/pnas.1719705115

Heo, J. O., Blob, B., and Helariutta, Y. (2017). Differentiation of conductive cells: a matter of life and death. Curr. Opin. Plant Biol. 35, 23-29. doi: 10.1016/j.pbi. 2016.10.007

Huysmans, M., Lema, A. S., Coll, N. S., and Nowack, M. K. (2017). Dying two deaths - programmed cell death regulation in development and disease. Curr. Opin. Plant Biol. 35, 37-44. doi: 10.1016/j.pbi.2016.11.005

Imkampe, J., Halter, T., Huang, S., Schulze, S., Mazzotta, S., Schmidt, N., et al. (2017). The Arabidopsis leucine-rich repeat receptor kinase BIR3 negatively regulates BAK1 receptor complex formation and stabilizes BAK1. Plant Cell 29, 2285-2303 doi: 10.1105/tpc.17.00376

Ito, J., and Fukuda, H. (2002). ZEN1 is a key enzyme in the degradation of nuclear DNA during programmed cell death of tracheary elements. Plant Cell 14, 3201-3211. doi: 10.1105/tpc.006411

Jeong, Y. J., Shang, Y., Kim, B. H., Kim, S. Y., Song, J. H., Lee, J. S., et al. (2010). BAK7 displays unequal genetic redundancy with BAK1 in brassinosteroid signaling and early senescence in Arabidopsis. Mol. Cells 29, 259-266. doi: 10.1007/s10059-010-0024-0

Jeworutzki, E., Roelfsema, M. R. G., Anschutz, U., Krol, E., Elzenga, J. T. M., Felix, G., et al. (2010). Early signaling through the Arabidopsis pattern recognition receptors FLS2 and EFR involves Ca2+-associated opening of plasma membrane anion channels. Plant J. 62, 367-378. doi: 10.1111/j.1365313X.2010.04155.x

Jones, A. M. (2001). Programmed cell death in development and defense. Plant Physiol. 125, 94-97. doi: 10.1104/pp.125.1.94

Jones, J. D., and Dangl, J. L. (2006). The plant immune system. Nature 444, 323-329. doi: 10.1038/nature05286

Kabbage, M., Kessens, R., Bartholomay, L. C., and Williams, B. (2017). The life and death of a plant cell. Annu. Rev. Plant Biol. 68, 375-404. doi: 10.1111/j.14698137.2010.03533.x

Kadota, Y., Sklenar, J., Derbyshire, P., Stransfeld, L., Asai, S., Ntoukakis, V., et al. (2014). Direct regulation of the NADPH oxidase RBOHD by the PRRassociated kinase BIK1 during plant immunity. Mol. Cell 54, 43-55. doi: 10. 1016/j.molcel.2014.02.021

Kemmerling, B., Schwedt, A., Rodriguez, P., Mazzotta, S., Frank, M., Qamar, S. A., et al. (2007). The BRI1-associated kinase 1, BAK1, has a brassinolideindependent role in plant cell-death control. Curr. Biol. 17, 1116-1122. doi: 10.1016/j.cub.2007.05.046

Kim, S. Y., Shang, Y., Joo, S. H., Kim, S. K., and Nam, K. H. (2017). Overexpression of BAK1 causes salicylic acid accumulation and deregulation of cell death control genes. Biochem. Biophys. Res. Commun. 484, 781-786. doi: 10.1016/j. bbrc.2017.01.166 
Kondo, Y., Ito, T., Nakagami, H., Hirakawa, Y., Saito, M., Tamaki, T., et al. (2014). Plant GSK3 proteins regulate xylem cell differentiation downstream of TDIF-TDR signalling. Nat. Commun. 5:3504. doi: 10.1038/ncomms4504

Kroemer, G., Galluzzi, L., Vandenabeele, P., Abrams, J., Alnemri, E. S., Baehrecke, E. H., et al. (2009). Classification of cell death: recommendations of the nomenclature committee on cell death 2009. Cell Death Differ. 16, 3-11. doi: $10.1038 / \mathrm{cdd} .2008 .150$

Kuriyama, H. (1999). Loss of tonoplast integrity programmed in tracheary element differentiation. Plant Physiol. 121, 763-774. doi: 10.1104/pp.121.3.763

Ladwig, F., Dahlke, R. I., Stuhrwohldt, N., Hartmann, J., Harter, K., and Sauter, M. (2015). Phytosulfokine regulates growth in Arabidopsis through a response module at the plasma membrane that includes CYCLIC NUCLEOTIDEGATED CHANNEL17, H+-ATPase, and BAK1. Plant Cell 27, 1718-1729. doi: $10.1105 /$ tpc. 15.00306

Lam, E., Kato, N., and Lawton, M. (2001). Programmed cell death, mitochondria and the plant hypersensitive response. Nature 411, 848-853. doi: 10.1038/ 35081184

Lam, E., Pontier, D., and del Pozo, O. (1999). Die and let live - programmed cell death in plants. Curr. Opin. Plant Biol. 2, 502-507. doi: 10.1016/S1369-5266(99) 00026-6

Levine, A., Pennell, R. I., Alvarez, M. E., Palmer, R., and Lamb, C. (1996). Calciummediated apoptosis in a plant hypersensitive disease resistance response. Curr. Biol. 6, 427-437. doi: 10.1016/S0960-9822(02)00510-9

Li, J. (2010). Multi-tasking of somatic embryogenesis receptor-like protein kinases. Curr. Opin. Plant Biol. 13, 509-514. doi: 10.1016/j.pbi.2010.09.004

Li, J., Wen, J., Lease, K. A., Doke, J. T., Tax, F. E., and Walker, J. C. (2002). BAK1, an Arabidopsis LRR receptor-like protein kinase, interacts with BRI1 and modulates brassinosteroid signaling. Cell 110, 213-222. doi: 10.1016/S00928674(02)00812-7

Li, J. Y., Jiang, A. L., and Zhang, W. (2007). Salt stress-induced programmed cell death in rice root tip cells. J. Integr. Plant Biol. 49, 481-486. doi: 10.1016/j. plaphy.2008.12.021

Li, W., Ahn, I. P., Ning, Y., Park, C. H., Zeng, L., Whitehill, J. G., et al. (2012). The U-Box/ARM E3 ligase PUB13 regulates cell death, defense, and flowering time in Arabidopsis. Plant Physiol. 159, 239-250. doi: 10.1104/pp.111.19 2617

Li, W., and Dickman, M. B. (2004). Abiotic stress induces apoptotic-like features in tobacco that is inhibited by expression of human Bcl-2. Biotechnol. Lett. 26, 87-95. doi: 10.1023/B:BILE.0000012896.76432.ba

Li, W., Kabbage, M., and Dickman, M. B. (2010). Transgenic expression of an insect inhibitor of apoptosis gene, SfIAP, confers abiotic and biotic stress tolerance and delays tomato fruit ripening. Physiol. Mol. Plant Pathol. 74, 363-375. doi: 10.1016/j.pmpp.2010.06.001

Li, Z., Wang, Y., Huang, J., Ahsan, N., Biener, G., Paprocki, J., et al. (2017). Two SERK receptor-like kinases interact with EMS1 to control anther cell fate determination. Plant Physiol. 173, 326-337. doi: 10.1104/pp.16.01219

Li, Z., Yue, H. Y., and Xing, D. (2012). MAP Kinase 6-mediated activation of vacuolar processing enzyme modulates heat shock-induced programmed cell death in Arabidopsis. New Phytol. 195, 85-96. doi: 10.1111/j.1469-8137.2012. 04131.x

Liebrand, T. W., van den Burg, H. A., and Joosten, M. H. (2014). Two for all: receptor-associated kinases SOBIR1 and BAK1. Trends Plant Sci. 19, 123-132. doi: 10.1016/j.tplants.2013.10.003

Lin, W., Li, B., Lu, D., Chen, S., Zhu, N., He, P., et al. (2014). Tyrosine phosphorylation of protein kinase complex BAK1/BIK1 mediates Arabidopsis innate immunity. Proc. Natl. Acad. Sci. U.S.A. 111, 3632-3637. doi: 10.1073/ pnas. 1318817111

Liu, J., Chen, S., Chen, L., Zhou, Q., Wang, M., Feng, D., et al. (2017). BIK1 cooperates with BAK1 to regulate constitutive immunity and cell death in Arabidopsis. J. Integr. Plant Biol. 59, 234-239. doi: 10.1111/jipb.12529

Liu, Y., Huang, X., Li, M., He, P., and Zhang, Y. (2016). Loss-of-function of Arabidopsis receptor-like kinase BIR1 activates cell death and defense responses mediated by BAK1 and SOBIR1. New Phytol. 212, 637-645. doi: 10.1111/nph. 14072

Liu, Y., Schiff, M., Czymmek, K., Talloczy, Z., Levine, B., and Dinesh-Kumar, S. P. (2005). Autophagy regulates programmed cell death during the plant innate immune response. Cell 121, 567-577. doi: 10.1016/j.cell.2005.03.007
Lu, D., Lin, W., Gao, X., Wu, S., Cheng, C., Avila, J., et al. (2011). Direct ubiquitination of pattern recognition receptor FLS2 attenuates plant innate immunity. Science 332, 1439-1442. doi: 10.1126/science.1204903

Ma, C., Liu, Y., Bai, B., Han, Z., Tang, J., Zhang, H., et al. (2017). Structural basis for BIR1-mediated negative regulation of plant immunity. Cell Res. 27, 1521-1524. doi: $10.1038 / \mathrm{cr} .2017 .123$

Ma, L., and Borhan, M. H. (2015). The receptor-like kinase SOBIR1 interacts with Brassica napus LepR3 and is required for Leptosphaeria maculans AvrLm1triggered immunity. Front. Plant Sci. 6:933. doi: 10.3389/fpls.2015.00933

Ma, X., Xu, G., He, P., and Shan, L. (2016). SERKing coreceptors for receptors. Trends Plant Sci. 21, 1017-1033. doi: 10.1016/j.tplants.2016. 08.014

Macho, A. P., and Zipfel, C. (2014). Plant PRRs and the activation of innate immune signaling. Mol. Cell. 54, 263-272. doi: 10.1016/j.molcel.2014.03.028

Meng, X., Chen, X., Mang, H., Liu, C., Yu, X., Gao, X., et al. (2015). Differential function of Arabidopsis SERK family receptor-like kinases in stomatal patterning. Curr. Biol. 25, 2361-2372. doi: 10.1016/j.cub.2015.07.068

Meng, X., Zhou, J., Tang, J., Li, B., de Oliveira, M. V. V., Chai, J., et al. (2016). Ligand-induced receptor-like kinase complex regulates floral organ abscission in Arabidopsis. Cell Rep. 14, 1330-1338. doi: 10.1016/j.celrep.2016.01.023

Mittler, R., Shulaev, V., and Lam, E. (1995). Coordinated activation of programmed cell death and defense mechanisms in transgenic tobacco plants expressing a bacterial proton pump. Plant Cell 7, 29-42. doi: 10.1105/tpc.7.1.29

Monaghan, J., and Zipfel, C. (2012). Plant pattern recognition receptor complexes at the plasma membrane. Curr. Opin. Plant Biol. 15, 349-357. doi: 10.1016/j.pbi. 2012.05.006

Nam, K. H., and Li, J. (2002). BRI1/BAK1, a receptor kinase pair mediating brassinosteroid signaling. Cell 110, 203-212. doi: 10.1016/S0092-8674(02) 00814-0

Overmyer, K., Brosche, M., Pellinen, R., Kuittinen, T., Tuominen, H., Ahlfors, R., et al. (2005). Ozone-induced programmed cell death in the Arabidopsis radicalinduced cell death1 mutant. Plant Physiol. 137, 1092-1104. doi: 10.1104/pp.104. 055681

Patel, S., Caplan, J., and Dinesh-Kumar, S. P. (2006). Autophagy in the control of programmed cell death. Curr. Opin. Plant Biol. 9, 391-396. doi: 10.1016/j.pbi. 2006.05.007

Peng, H. C., and Kaloshian, I. (2014). The tomato leucine-rich repeat receptorlike kinases SISERK3A and SISERK3B have overlapping functions in bacterial and nematode innate immunity. PLoS One 9:e93302. doi: 10.1371/journal.pone. 0093302

Peng, H. C., Mantelin, S., Hicks, G. R., Takken, F. L., and Kaloshian, I. (2016). The conformation of a plasma membrane-localized somatic embryogenesis receptor kinase complex is altered by a potato aphid-derived effector. Plant Physiol. 171, 2211-2222. doi: 10.1104/pp.16.00295

Pennell, R. I., and Lamb, C. (1997). Programmed cell death in plants. Plant Cell 9, 1157-1168. doi: 10.1105/tpc.9.7.1157

Perraki, A., DeFalco, T. A., Derbyshire, P., Avila, J., Sere, D., Sklenar, J., et al. (2018). Phosphocode-dependent functional dichotomy of a common coreceptor in plant signalling. Nature 561, 248-252. doi: 10.1038/s41586-0180471-x

Petrov, V., Hille, J., Mueller-Roeber, B., and Gechev, T. S. (2015). ROS-mediated abiotic stress-induced programmed cell death in plants. Front. Plant Sci. 6:69. doi: 10.3389/fpls.2015.00069

Postel, S., Kufner, I., Beuter, C., Mazzotta, S., Schwedt, A., Borlotti, A., et al. (2010). The multifunctional leucine-rich repeat receptor kinase BAK1 is implicated in Arabidopsis development and immunity. Eur. J. Cell Biol. 89, 169-174. doi: 10.1016/j.ejcb.2009.11.001

Postma, J., Liebrand, T. W., Bi, G., Evrard, A., Bye, R. R., Mbengue, M., et al. (2016). Avr4 promotes Cf- 4 receptor-like protein association with the BAK1/SERK3 receptor-like kinase to initiate receptor endocytosis and plant immunity. New Phytol. 210, 627-642. doi: 10.1111/nph.13802

Pyo, H., Demura, T., and Fukuda, H. (2007). TERE; a novel cis-element responsible for a coordinated expression of genes related to programmed cell death and secondary wall formation during differentiation of tracheary elements. Plant J. 51, 955-965. doi: 10.1111/j.1365-313X.2007.03180.x

Qi, Y., Tsuda, K., Glazebrook, J., and Katagiri, F. (2011). Physical association of pattern-triggered immunity (PTI) and effector-triggered immunity (ETI) 
immune receptors in Arabidopsis. Mol. Plant Pathol. 12, 702-708. doi: 10.1111/ j.1364-3703.2010.00704.x

Raff, M. (1998). Cell suicide for beginners. Nature 396, 119-122. doi: 10.1038/24055

Rantong, G., and Gunawardena, A. H. L. A. N. (2015). Programmed cell death: genes involved in signaling, regulation, and execution in plants and animals. Botany 93, 193-210. doi: 10.1139/cjb-2014-0152

Saijo, Y. (2010). ER quality control of immune receptors and regulators in plants. Cell Microbiol. 12, 716-724. doi: 10.1111/j.1462-5822.2010.01472.x

Schmidt, E. D., Guzzo, F., Toonen, M. A., and de Vries, S. C. (1997). A leucine-rich repeat containing receptor-like kinase marks somatic plant cells competent to form embryos. Development 124, 2049-2062.

Schulze, B., Mentzel, T., Jehle, A. K., Mueller, K., Beeler, S., Boller, T., et al. (2010). Rapid heteromerization and phosphorylation of ligand-activated plant transmembrane receptors and their associated kinase BAK1. J. Biol. Chem. 285, 9444-9451. doi: 10.1074/jbc.M109.096842

Schwessinger, B., Roux, M., Kadota, Y., Ntoukakis, V., Sklenar, J., Jones, A., et al. (2011). Phosphorylation-dependent differential regulation of plant growth, cell death, and innate immunity by the regulatory receptor-like kinase BAK1. PLoS Genet 7:e1002046. doi: 10.1371/journal.pgen.1002046

Serrano, I., Romero-Puertas, M. C., Sandalio, L. M., and Olmedilla, A. (2015). The role of reactive oxygen species and nitric oxide in programmed cell death associated with self-incompatibility. J. Exp. Bot. 66, 2869-2876. doi: 10.1093/ jxb/erv083

Shan, L., He, P., Li, J., Heese, A., Peck, S. C., Nürnberger, T., et al. (2008). Bacterial effectors target the common signaling partner BAK1 to disrupt multiple MAMP receptor-signaling complexes and impede plant immunity. Cell Host Microbe 4, 17-27. doi: 10.1016/j.chom.2008.05.017

Shen, Z. L., Lai, Y. C., Wong, C. H., Goh, K. K., Yang, Y. S., Cheong, H. L., et al. (2011). Palladium-catalyzed cross-coupling of indium homoenolate with aryl halide with wide functional group compatibility. Org. Lett. 13, 422-425. doi: 10.1021/ol102755q

Song, W. Y., Wang, G. L., Chen, L. L., Kim, H. S., Pi, L. Y., Holsten, T., et al. (1995). A receptor kinase-like protein encoded by the rice disease resistance gene, Xa21. Science 270, 1804-1806. doi: 10.1126/science.270.5243.1804

Sun, T., Zhang, Q., Gao, M., and Zhang, Y. (2014). Regulation of SOBIR1 accumulation and activation of defense responses in bir1-1 by specific components of ER quality control. Plant J. 77, 748-756. doi: 10.1111/tpj.12425

Szekeres, M., Nemeth, K., Koncz-Kalman, Z., Mathur, J., Kauschmann, A., Altmann, T., et al. (1996). Brassinosteroids rescue the deficiency of CYP90, a cytochrome P450, controlling cell elongation and de-etiolation in Arabidopsis. Cell 85, 171-182. doi: 10.1016/S0092-8674(00)81094-6

Tang, D., Wang, G., and Zhou, J. M. (2017). Receptor kinases in plant-pathogen interactions: more than pattern recognition. Plant Cell 29, 618-637. doi: 10. $1105 /$ tpc. 16.00891

Turner, S., Gallois, P., and Brown, D. (2007). Tracheary element differentiation. Annu. Rev. Plant Biol. 58, 407-433. doi: 10.1146/annurev.arplant.57.032905.105236

van Doorn, W. G. (2011). Classes of programmed cell death in plants, compared to those in animals. J. Exp. Bot. 62, 4749-4761. doi: 10.1093/jxb/err196

van Doorn, W. G., Beers, E. P., Dangl, J. L., Franklin-Tong, V. E., Gallois, P., HaraNishimura, I., et al. (2011). Morphological classification of plant cell deaths. Cell Death Differ. 18, 1241-1246. doi: 10.1038/cdd.2011.36

Van Hautegem, T., Waters, A. J., Goodrich, J., and Nowack, M. K. (2015). Only in dying, life: programmed cell death during plant development. Trends Plant Sci. 20, 102-113. doi: 10.1016/j.tplants.2014.10.003

Wang, H., Li, J., Bostock, R. M., and Gilchrist, D. G. (1996). Apoptosis: a functional paradigm for programmed plant cell death induced by a hostselective phytotoxin and invoked during development. Plant Cell 8, 375-391. doi: $10.1105 /$ tpc.8.3.375

Wang, Z., Meng, P., Zhang, X., Ren, D., and Yang, S. (2011). BON1 interacts with the protein kinases BIR1 and BAK1 in modulation of temperature-dependent plant growth and cell death in Arabidopsis. Plant J. 67, 1081-1093. doi: 10.1111/ j.1365-313X.2011.04659.x

Wierzba, M. P., and Tax, F. E. (2016). An allelic series of bak1 mutations differentially alter bir1 cell death, immune response, growth, and root development phenotypes in Arabidopsis thaliana. Genetics 202, 689-702. doi: 10.1534/genetics.115.180380
Williams, B., and Dickman, M. (2008). Plant programmed cell death: can't live with it; can't live without it. Mol. Plant Pathol. 9, 531-544. doi: 10.1111/j.1364-3703. 2008.00473.x

Wu, C. H., Derevnina, L., and Kamoun, S. (2018). Receptor networks underpin plant immunity. Science 360, 1300-1301. doi: 10.1126/science.aat2623

Wu, L., Chen, H., Curtis, C., and Fu, Z. Q. (2014). Go in for the kill How plants deploy effector-triggered immunity to combat pathogens. Virulence 5, 710-721. doi: 10.4161/viru.29755

Wu, W., Wu, Y., Gao, Y., Li, M., Yin, H., Lv, M., et al. (2015). Somatic embryogenesis receptor-like kinase 5 in the ecotype Landsberg erecta of Arabidopsis is a functional RD LRR-RLK in regulating brassinosteroid signaling and cell death control. Front. Plant Sci. 6:852. doi: 10.3389/fpls.2015.00852

Xu, H. Y., Zhang, C., Li, Z. C., Wang, Z. R., Jiang, X. X., Shi, Y. F., et al. (2018). The MAPK kinase kinase GmMEKK1 regulates cell death and defense responses. Plant Physiol. 178, 907-922 doi: 10.1104/pp.18.00903

Xu, T., Nicolson, S., Denton, D., and Kumar, S. (2015). Distinct requirements of autophagy-related genes in programmed cell death. Cell Death Differ. 22, 1792-1802. doi: 10.1038/cdd.2015.28

Yadeta, K. A., Elmore, J. M., Creer, A. Y., Feng, B., Franco, J. Y., Rufian, J. S., et al. (2016). A cysteine-rich protein kinase associates with a membrane immune complex and is required for cell death. Plant Physiol. 173, 771-787. doi: 10.1104/ pp.16.01404

Yadeta, K. A., Elmore, J. M., Creer, A. Y., Feng, B., Franco, J. Y., Rufian, J. S., et al. (2017). A cysteine-rich protein kinase associates with a membrane immune complex and the cysteine residues are required for cell death. Plant Physiol. 173, 771-787. doi: 10.1104/pp.16.01404

Yamada, K., Yamashita-Yamada, M., Hirase, T., Fujiwara, T., Tsuda, K., Hiruma, K., et al. (2016). Danger peptide receptor signaling in plants ensures basal immunity upon pathogen-induced depletion of BAK1. EMBO J. 35, 46-61. doi: $10.15252 /$ embj.201591807

Yamamoto, R., Demura, T., and Fukuda, H. (1997). Brassinosteroids induce entry into the final stage of tracheary element differentiation in cultured Zinnia cells. Plant Cell Physiol. 38, 980-983. doi: 10.1093/oxfordjournals.pcp.a02 9262

Yasuda, S., Okada, K., and Saijo, Y. (2017). A look at plant immunity through the window of the multitasking coreceptor BAK1. Curr. Opin. Plant Biol. 38, 10-18. doi: 10.1016/j.pbi.2017.04.007

Yu, X. H., Perdue, T. D., Heimer, Y. M., and Jones, A. M. (2002). Mitochondrial involvement in tracheary element programmed cell death. Cell Death Differ. 9 , 189-198. doi: 10.1038/sj.cdd.4400940

Zakeri, Z., Bursch, W., Tenniswood, M., and Lockshin, R. A. (1995). Cell-death programmed, apoptosis, necrosis, or other. Cell Death Differ. 2, 87-96.

Zhang, H., Lin, X., Han, Z., Wang, J., Qu, L. J., and Chai, J. (2016). SERK family receptor-like kinases function as co-receptors with PXY for plant vascular development. Mol. Plant 9, 1406-1414. doi: 10.1016/j.molp.2016.07.004

Zhang, S. L., and Tang, H. (2005). Autophagy: type II programmed cell death. Prog. Biochem. Biophys. 32, 1011-1015.

Zhang, S. Z., Liu, X. G., Lin, Y. A., Xie, G. N., Fu, F. L., Liu, H., et al. (2011). Characterization of a ZmSERK gene and its relationship to somatic embryogenesis in a maize culture. Plant Cell Tissue Organ Cult. 105, 29-37. doi: 10.1007/s11240-010-9834-1

Zhang, W., Fraiture, M., Kolb, D., Loffelhardt, B., Desaki, Y., Boutrot, F. F., et al. (2013). Arabidopsis receptor-like protein30 and receptor-like kinase suppressor of BIR1-1/EVERSHED mediate innate immunity to necrotrophic fungi. Plant Cell 25, 4227-4241. doi: 10.1105/tpc.113.117010

Zhang, Z., Wu, Y., Gao, M., Zhang, J., Kong, Q., Liu, Y., et al. (2012). Disruption of PAMP-induced MAP kinase cascade by a Pseudomonas syringae effector activates plant immunity mediated by the NB-LRR protein SUMM2. Cell Host Microbe 11, 253-263. doi: 10.1016/j.chom.2012.01.015

Zhong, R., Lee, C., and Ye, Z. H. (2010). Global analysis of direct targets of secondary wall NAC master switches in Arabidopsis. Mol. Plant 3, 1087-1103. doi: $10.1093 / \mathrm{mp} / \mathrm{ssq} 062$

Zhou, J., Wu, S., Chen, X., Liu, C., Sheen, J., Shan, L., et al. (2014). The Pseudomonas syringae effector HopF2 suppresses Arabidopsis immunity by targeting BAK1. Plant J. 77, 235-245. doi: 10.1111/tpj.12381

Zhu, W., Ronen, M., Gur, Y., Minz-Dub, A., Masrati, G., Ben-Tal, N., et al. (2017). BcXYG1, a secreted xyloglucanase from botrytis cinerea, triggers both cell death 
and plant immune responses. Plant Physiol. 175, 438-456. doi: 10.1104/pp.17. 00375

Zipfel, C. (2014). Plant pattern-recognition receptors. Trends Immunol. 35, 345351. doi: 10.1016/j.it.2014.05.004

Zipfel, C., Kunze, G., Chinchilla, D., Caniard, A., Jones, J. D., Boller, T., et al. (2006). Perception of the bacterial PAMP EF-Tu by the receptor EFR restricts Agrobacterium-mediated transformation. Cell 125, 749-760. doi: 10.1016/j.cell. 2006.03.037

Zuppini, A., Andreoli, C., and Baldan, B. (2007). Heat stress: an inducer of programmed cell death in Chlorella saccharophila. Plant Cell Physiol. 48, 1000-1009. doi: 10.1093/pcp/pcm070
Conflict of Interest Statement: The authors declare that the research was conducted in the absence of any commercial or financial relationships that could be construed as a potential conflict of interest.

Copyright (c) 2019 Gao, Ruan, Sun, Wang and Feng. This is an open-access article distributed under the terms of the Creative Commons Attribution License (CC BY). The use, distribution or reproduction in other forums is permitted, provided the original author(s) and the copyright owner(s) are credited and that the original publication in this journal is cited, in accordance with accepted academic practice. No use, distribution or reproduction is permitted which does not comply with these terms. 